\title{
МАЛЫЙ И СРЕДНИЙ БИЗНЕС: ТРЕНДЫ ПРЕДПРИНИМАТЕЛЬСКОЙ ДЕЯТЕЛЬНОСТИ В ПАНДЕМИЮ КОРОНАВИРУСА
}

\author{
(C) 2021 Волкодавова Елена Викторовна \\ доктор экономических наук, профессор \\ Самарский государственный экономический университет, Россия, Самара \\ E-mail:vev.sseu@gmail.com
}

Пандемия коронавируса вызвала глобальные изменения во многих странах мира, определяя ключевые тренды технологических изменений и условий хозяйственной деятельности, заставляя агентов глобального рынка искать инструменты и методы адаптации к работе в новых условиях. Предприятия малого и среднего бизнеса, сохранившие свои позиции в занимаемых сегментах рынка, вынуждены искать новые методы и пути функционирования и развития. В статье исследованы возможные технологические тренды 2021 года, и на примере российских предприятий рециклинга, показана возможность успешного функционирования субъектов российского малого и среднего бизнеса в посткоронавирусной экономике.

Ключевые слова: кризисные явления, пандемия, малые и средние предприятия, тренды предпринимательской деятельности, инструменты адаптация к условиям рынка.

Введение. Весь мир переживает сложную ситуацию, связанную с ограничениями в осуществлении бизнеса, перемещении в глобальном пространстве, кардинальном изменении образа и качества жизни населения многих стран. И все это связано с пандемией коронавируса, внесшей существенные коррективы, в проектирование, организацию и инвестирование существующих бизнес-моделей, в том числе, малых и средних предприятий. Увеличение факторов неопределенности ведения бизнеса требуют от предпринимательских структур всех размеров перестроиться, адаптироваться к жизни в новых экономических условиях. Но тем малым и средним предприятиям, которые выжили в сложный период 2020 года, сделать это гораздо труднее, чем представителям крупного бизнеса. В данной статье автор сделала попытку проанализировать сложившиеся технологические тенденции бизнеса в 2021 году и возможности малых и средних предприятий в успешном осуществлении бизнеса.

Теория. Предприятия малого и среднего бизнеса (МСБ) являются драйверами развития экономик многих стран. По данным Организации Объединенный Наций $(\mathrm{OOH})$, к категории МСБ относятся около $90 \%$ всех предприятий в мире. В них заняты приблизительно 70\% трудоспособного населения, на их долю приходится более 50\% мирового ВВП [1].

Доля продукции российских предприятий малого и среднего бизнеса в ВВП в 2017-2019 г.г. снизилась с $22 \%$ до 20,2\% (см. табл.2). Сложившаяся тенденция является вполне понятной, если учитывать условия для ведения бизнеса в относительно стабильные 2017-2019 годы.

Таблица 1. Доля малых и средних предприятий в ВВП стран в 2019 г.

\begin{tabular}{|l|c|c|l|c|c|}
\hline \multirow{2}{*}{ Страна } & \multicolumn{2}{|c|}{ Доля в ВВП страны,\% } & \multicolumn{2}{|c|}{ Доля в ВВП,\% } \\
\cline { 2 - 3 } \cline { 5 - 6 } & $\begin{array}{c}\text { малых и средних } \\
\text { предприятий }\end{array}$ & $\begin{array}{c}\text { предприятий } \\
\text { крупного биз- } \\
\text { неса }\end{array}$ & $\begin{array}{c}\text { Салых и средних } \\
\text { предприятий }\end{array}$ & $\begin{array}{c}\text { предприятий } \\
\text { крупного биз- } \\
\text { неса }\end{array}$ \\
\hline Россия & 21 & 79 & Швейцария & 59 & 41 \\
\hline Корея & 48 & 52 & Финляндия & 60 & 40 \\
\hline Великобритания & 51 & 49 & Израиль & 60 & 40 \\
\hline Германия & 53 & 47 & Норвегия & 61 & 39 \\
\hline Австралия & 58 & 42 & Нидерланды & 63 & 37 \\
\hline Швеция & 58 & 42 & Италия & 68 & 32 \\
\hline
\end{tabular}

Источник: Составлено автором на основе данных официального сайта Российской венчурной компании, https://www.rvc.ru/ [2] 
Таблица 2. Динамика доли российского малого и среднего предпринимательства в ВВП

\begin{tabular}{|c|c|c|c|c|c|}
\hline Годы & 2017 & 2018 & 2019 & 2020 & 2024, проект \\
\hline Доля МСБ в ВВП, \% & 22 & 20,4 & 20,6 & 20,2 & $32,5^{*}$ \\
\hline
\end{tabular}

Источник: Составлено автором на основании данных с официального сайта Российской Государственной статистики, https://www.gks.ru/ [3]

* Прогнозное значение, представленное в паспорте Национального проекта Малое и среднее предпринимательство и поддержка индивидуальной предпринимательской инициативы» http://government.ru/info/35563/ [4]

Если рассматривать тенденцию динамики, представленную в табл.2, то можно утверждать, что доля МСБ в ВВП в 2020 году существенно не сократилась. Это свидетельствует о том, что представители российского МСБ ищут новые рыночные ниши и прилагают все возможные усилия, чтобы остаться в завоеванных сегментах. Учитывая, что в паспорте национального проекта «Малое и среднее предпринимательство и поддержка индивидуальной предпринимательской инициативы» [4], одной из основных целей является увеличение доли малого и среднего бизнеса в ВВП страны к 2024 году до 32,5\%. очень важно исследовать тенденции развития российских технологий и то место, которое могут в них занять представители МСБ.

По этому поводу ведутся различные исследования. Например, в статье Жабина А.П., ВолкодавовойЕ.В. «К вопросу о развитии методологии исследования трендов предпринимательской деятельности» [5] изложена методология исследования трендов бизнеса малых и средних предприятий (МСП). В исследованиях [6,7,8], анализируются современные тренды развития технологий, возможности и опасения предприятий МСБ в их применении.

В отчете по результатам исследованиях российской венчурной компании в июле-августе 2020 года «Отношение населения к новым технологиям в период коронакризиса» [2], сделан акцент на том, что отношение людей к предпринимательству и новым технологиям зависит от сложившейся экономической ситуации, определяющей во многом их потребительские характеристики. В данном отчете отмечаются новые тренды технологического предпринимательства, сложившиеся под влиянием жизни и работы людей в условиях посткоронавирусной экономики. Эти условия стимулируют предпринимателей осваивать новые направления инновационных технологий и, прежде всего безлюдных, таких как применение дронов, беспилотных транспортных систем и другой робототехники, которые в условиях пандемии обеспечат мониторинг соблюдения карантинных требований, доставку почты, продуктов, медикаментов и пр. населению. При таком взаимодействии с потребителями различных услуг, не возникает контактов и опасений распространения инфекции.

В исследовании «ТОП 15 трендов бизнеса и технологий в 2021 году», представленном в [6], изложены ключевые технологии, которые могут оказать существенное влияние на развитие бизнеса. К ним относятся, дистанционные сотрудники (перешедшие на «удаленный метод работы») и услуги, а также сервисы для цифровых кочевников; персонализация всего; высокие технологии в пищевой промышленности; маркетплейсы; экосистемы и супераппы; масштабное внедрение блокчейна; зеленый бизнес; переработка отходов: виртуальная и дополненная реальность; кибербезопасность; умные здания; телемедицина; виртуальные персонажи; серебро дороже золота.

Конечно, не все эти технологии доступны малым и средним предприятиям, т.к. реализация многих из них требует привлечения инвестиций.

Данные и методы. Теоретической и методологической основой исследования выступают: методы системного и комплексного анализа, позволяющие исследовать проблемы и возможности функционирования и развития предприятий малого и среднего бизнеса в условиях пандемии; экспертный метод, с помощью которого был проведен опрос среди специалистов предприятий рециклинга Самарской области и дана оценка его результатов.

Экспериментальная база исследования российские предприятия малого и среднего бизнеса.

Результаm. Если рассматривать топ - технологии 2021 года, приведенные в исследованиях, то можно с уверенностью сказать, что в применении этих трендовых технологий посткоронавирусной экономики, таких, например, как умный дом, дистанционные сотрудники и услуги, переработка отходов и др. есть место и для малых и средних российских предприятий.

Рассмотрим, на примере предприятий рециклинга, одну из рыночных ниш, которую в 
настоящее время могут успешно занимать представители российского МСБ. Нишу переработки возвратных химических отходов малые и средние предприятия, осуществляющие рециклинг, занимали и до пандемии коронавируса. Но, конечно, в существующей неопределенности экономической среды этот бизнес претерпевает существенные трудности. С целью выявления условий и проблем осуществления бизнеса в 2021 году среди менеджеров и работников пред- приятий рециклинга был проведен социологический опрос.

В опросе принимали участие представители российских малых и средних предприятий Самарской области, осуществляющие переработку возвратных химических отходов в 2021 году.

Результаты опроса менеджмента российских малых предприятий рециклинга о функционировании бизнеса в условиях пандемии коронавируса представлены в таблице 3.

Таблица 3. Результаты опроса менеджеров малых и средних предприятий рециклинга

\begin{tabular}{|c|c|}
\hline Вопрос & Результат \\
\hline $\begin{array}{l}\text { 1. Сократилось ли Ваше производство в прошедшем } \\
2020 \text { году? }\end{array}$ & $\begin{array}{l}\text { 73\% респондентов отметили, что производство не } \\
\text { сократилось } \\
27 \% \text { ответили, что производство сократилось }\end{array}$ \\
\hline $\begin{array}{l}\text { 2. Опасаетесь ли Вы инвестировать в развитие новых } \\
\text { технологий? }\end{array}$ & $\begin{array}{l}\text { 85\% респондентов не опасаются инвестировать в } \\
\text { новые технологии } \\
\text { 15\% испытывают опасения }\end{array}$ \\
\hline 3. Доступны ли кредиты на развитие производства & \multirow{2}{*}{$\begin{array}{l}\text { 55\% респондентов отметили доступность кредитов и } \\
\text { кредитных условий } \\
45 \% \text { респондентов отметили сложность в получении } \\
\text { кредитов и неблагоприятные условия кредитования }\end{array}$} \\
\hline 4. Устраивают ли условия кредитования? & \\
\hline $\begin{array}{l}\text { 5. Нуждается ли существующая бизнес-модель в } \\
\text { корректировке? }\end{array}$ & $\begin{array}{l}\text { 92\% респондентов отметили, что в настоящее время } \\
\text { нет условий для перехода к новой бизнес- модели } \\
8 \% \text { респондентов затруднились ответить }\end{array}$ \\
\hline $\begin{array}{l}\text { 6. Нуждаетесь ли в обучении технологиям функцио- } \\
\text { нирования в кризисной среде? }\end{array}$ & $\begin{array}{l}\text { 67\% респондентов нуждаются в обучении функцио- } \\
\text { нирования в кризисной среде } \\
\text { 33\% респондентов ответили, что такой необходимо- } \\
\text { сти нет }\end{array}$ \\
\hline 7. Планируете ли расширение бизнеса? & $\begin{array}{l}\text { 65\% респондентов планирует расширение бизнеса в } \\
\text { ближайшие } 3 \text { года } \\
\text { 35\% не планируют, т.к опасаются потерять средства, } \\
\text { вложенные в расширение бизнеса }\end{array}$ \\
\hline 8. Какая необходима помощь? & $\begin{array}{l}\text { 72\% респондентов отметили, что нуждаются в } \\
\text { информационной и инфраструктурной поддержке } \\
\text { бизнеса, а также помощи в получении кредитов на } \\
\text { более выгодных условиях. } \\
28 \% \text { респондентов хотели бы получить от государства } \\
\text { и региональных властей субсидии. }\end{array}$ \\
\hline $\begin{array}{l}\text { 9. Есть ли у вас трудности в поиске и подборе персо- } \\
\text { нала компании? }\end{array}$ & $\begin{array}{l}\text { 45\% респондентов не имеют трудностей с подбором } \\
\text { персонала. } \\
55 \% \text { респондентов имеют некоторые трудности с } \\
\text { подбором персонала. } \\
\text { Комментарии респондентов: трудности связаны с } \\
\text { тем, что работа с отходами относится к «непривле- } \\
\text { кательным» сферам трудовой деятельности. Соот- } \\
\text { ветственно, собирать, сортировать, отмывать отходы } \\
\text { идут кадры без образования, лица, приезжающие с } \\
\text { ближнего зарубежья }\end{array}$ \\
\hline $\begin{array}{l}\text { 10. Как Вы оцениваете уровень развития партнерских } \\
\text { хозяйственных связей в регионе? (в т.ч. со сборщика- } \\
\text { ми отходов и производителями химической первич- } \\
\text { ной продукции) }\end{array}$ & $\begin{array}{l}\text { 10\% респондентов «полностью удовлетворены» пар- } \\
\text { тнерскими хозяйственными связями своего бизнеса, } \\
\text { 60\% респондентов оценивают уровень развития } \\
\text { партнерских хозяйственных связей как «удовлетво- } \\
\text { рительно». } \\
\text { 30\% поставили «неудовлетворительно» }\end{array}$ \\
\hline $\begin{array}{l}\text { 11. Существуют ли «перебои» с сырьем (в т.ч.. всегда } \\
\text { ли предприниматель имеет доступ к подобным «от- } \\
\text { ходам» или есть необходимость поиска сырья, вплоть } \\
\text { до закупки из других субъектов РФ) }\end{array}$ & $\begin{array}{l}\text { 75\% респондентов не испытывает проблем с сырьем } \\
\text { в регионе } \\
25 \% \text { испытывает проблемы с сырьем, потребляемым } \\
\text { из региона базирования предприятия }\end{array}$ \\
\hline
\end{tabular}


В результате проведенного анкетирования управленческого состава российских малых предприятий рециклинга удалось выявить как положительные тренды по условиям и работы в пандемию коронавируса, так и отрицательные. Среди положительных тенденций стоит отметить готовность субъектов малого бизнеса инвестировать денежные средства в развитие технологий переработки отходов и дальнейшего производства готовых продуктов (85\% респондентов), а также перспективные планы на расширение бизнеса (65\% респондентов), что свидетельствует об определенной антикризисной устойчивости данных предприятий. Однако, много респондентов (67\%) отметили, что нуждаются в обучении функционирования в кризисной среде, в целях преодоления влияния неблагоприятных факторов воздействия внешней среды на бизнес, испытывают трудности в подборе персонала (55\%). Сохранились и традиционные, существующие до пандемии коронавируса проблемы с информационной и инфраструктурной поддержкой бизнеса в регионе, получением кредитов на привлекательных условиях, а также с поиском, подбором и «текучестью» кадров в анализируемой сфере бизнеса.

В целом же, из результата опроса видно, что российские предприятия переработки химических отходов имеют возможность для функционирования бизнеса в современных условиях хозяйствования. И этому способствуют инструменты адаптации, которые в виде мер поддержки бизнеса постоянно предпринимает Правительство РФ. К этим инструментам относятся: отсрочка уплаты налогов и прочих платежей, льготное кредитование, субсидирование, специальная кредитная программа поддержки занятости и др. У каждого предпринимателя есть возможность ознакомиться с актуальными мерами поддержки бизнеса на действующем сайте СТОПКОРОНАВИРУС.РФ [9].
Кроме этого, Федеральная служба государственной статистики раз в пять лет проводит исследование, связанное с анализом условий, в которых работают субъекты российского МСБ, чтобы оценить их актуальные насущные потребности и определить характер ожиданий действенной помощи от Правительства РФ. Как раз такое исследование «Экономическая перепись малого бизнеса» проводилось в первом полугодии 2021 года. с 15 января по 1 апреля [10]. В нем приняли участие средние и малые предприятия, микропредприятия и индивидуальные предприниматели, которые представили сведения о своей деятельности в 2020 году в предложенных на сайте формах федерального статистического наблюдения, в т.ч.: о виде экономической деятельности, параметрах производственной деятельности, стоимости и составе основных средств производства.

После предоставления руководством предприятий МСБ достоверных данных о деятельности в современной экономической среде, у государственных органов появится возможность разработать новые направления и меры стимулирования деятельности и развития малого и среднего бизнеса.

Выводы. На основании результатов выполненного исследования можно утверждать, что у российских малых и средних предприятий есть возможность органично адаптироваться к новым условиям ведения бизнеса.

Российское правительство предпринимает все возможные меры, помогающие адаптировать бизнес малых и средних предприятий к условиям посткоронавирусной экономики.

Данные полевых исследований на примере российских малых и средних предприятий рециклинга убедительно доказывают, что у них есть не только возможность, но и актуальные действенные меры адаптации бизнеса к современной экономической среде.

\section{Библиографический список}

1. Официальный сайт Организации Объединенных Наций.- Режим доступа: https://www.un.org/ru/ observances/micro-small-medium-businesses-day/ (Дата обращения 15.04.2021)

2. РВК. «Отношение населения к новым технологиям в период коронакризиса» https://www.rvc.ru/upload/ iblock/fd8/RVC_attitudes_to_technologies_report2020_fragment.pdf (Дата обращения 12.04.2021)

3. Официальный сайт Федеральной службы государственной статистики.- Режим доступа: обращения https://www.gks.ru/ (Дата обращения 15.04.2021)

4. Паспорт национального проекта «Малое и среднее предпринимательство и поддержка индивидуальной предпринимательской инициативы» http://government.ru/info/35563/(Дата обращения 12.04.2021) 
5. Жабин А.П., Волкодавова Е. В. К вопросу о развитии методологии исследования трендов предпринимательской деятельности. Экономика и предпринимательство. 2018. № 7 (96). С. 743-747.

6. B-MAG, деловая жизнь сегодня. ТОП 15 трендов бизнеса и технологий в 2021 году https://b-mag.ru/ top-15-trendov-biznesa-i-tehnologij-v-2021-godu/ (Дата обращения 15.04.2021)

7. Idealistworld Развитие бизнеса. Бизнес тренды 2021 года - что дальше? https://www.idealistworld.com/ osnovnaya-tema/myishlenie/biznes-trendy-2021/(Дата обращения 15.04.2021)

8. TADVISER Государство. Бизнес. ИT. «Райффайзенбанк» назвал главные страхи малого бизнеса в России. https://www.tadviser.ru/index.php/\%D0\%A1\%D1\%82\%D0\%B0\%D1\%82\%D1\%8C\%D1\%8F:\%D0\%9C\%D0 \%B0\%D0\%BB\%D1\%8B\%D0\%B9_\%D0\%B1\%D0\%B8\%D0\%B7\%D0\%BD\%D0\%B5\%D1\%81_\%D0\%A0\%D0\%BE\% D1\%81\%D1\%81\%D0\%B8\%D0\%B8\#.D0.92.D1.8B.D1.80.D1.83.D1.87.D0.BA.D0.B0_.D0.BC.D0.B0.D0.BB.D0.BE. D0.B3.D0.BE_D0.B1.D0.B8.D0.B7.D0.BD.D0.B5.D1.81.D0.B0_.D1.80.D1.83.D1.85.D0.BD.D1.83.D0.BB.D0.B0_. D0.BD.D0.B0_2.2C8_D1.82.D1.80.D0.BB.D0.BD_D1.80.D1.83.D0.B1.D0.BB.D0.B5.D0.B92021 (Дата обращения 12.04.2021)

9. «Официальная информация о коронавирусе в России» Информационный ресурс https://xn-80aesfpebagmfblc0a.xn - p1ai/what-to-do/business/ (Дата обращения 05.04.2020)

10. Федеральная служба государственной статистики. Сплошное статистическое наблюдение малого и среднего бизнеса за 2020 год ttps://rosstat.gov.ru/small_business_2020 (Дата обращения 18.03.2020.) 